\title{
APHRONS OBTAINED FROM DIFFERENT NONIONIC SURFACTAN TS: PROPERTIES AND FILTRATION LOSS EVALUATION
}

\author{
Lais Gomes ${ }^{1, *}$, Bruna Alves ${ }^{1}$, Rita de Cassia Nunes ${ }^{1}$, Ricardo Michel ${ }^{2}$, Ygor Ribeiro1, \\ Flavia da Silva ${ }^{1}$, Luciana Spinelli ${ }^{1,3}$
}

https:

\begin{abstract}
Aphrons were produced using nonionic surfactants by applying a differential pressure. Bubble size distribution was obtained from optical microscopy using FIJI-ImageJ2 program. The aim of this work was to correlate surfactants structures with aphrons properties (density and viscosity), size distribution and the number of bubbles. API fluid loss tests were based on standard proceedings specifications for water-based drilling fluids of Petrobras/Brazil. The structure of the nonionic surfactants showed a great influence on the fluid properties and the performance of the fluid contributing with a filtrate reduction up to $31 \%$ with the systems that were presented between 1088 and 1850 bubbles with diameters ranging from 33 to $104 \mu \mathrm{m}$. These systems were produced by poly(ethylene oxide) with 7 ethylene oxide units, a poly(ethylene oxide)-b-poly(propylene oxide) with 6 ethylene oxide units and 3 propylene oxide units.
\end{abstract}

Keywords: aphrons, nonionic surfactants, bubbles, filtrate reduction, image analysis.

\section{Introduction}

A classical definition of colloidal gas aphron (CGA), proposed by Sebba [1-2], is a dispersion of bubbles formed by a gaseous core thermodynamically stabilized by a surfactant multi-layered structure. One inner shell supports the gaseous core and separates it from a viscous water phase. Then, a double surfactant layer maintains this whole

\footnotetext{
${ }^{1}$ Universidade Federal do Rio de Janeiro, Instituto de Macromoléculas, Laboratório de Macromoléculas e Colóides na Indústria de Petróleo, Av. Horácio Macedo, 2030, Ilha do Fundão, Rio de Janeiro, Brazil, 21941598.

${ }^{2}$ Universidade Federal do Rio de Janeiro, Instituto de Química, Departamento de Química Analítica. Av. Athos da Silveira Ramos 149, Ilha do Fundão, Rio de Janeiro, Brazil, 21941598.

${ }^{3}$ Universidade Federal do Rio de Janeiro, Instituto Alberto Luiz Coimbra de Pós-Graduação e Pesquisa em Engenharia, Programa de Engenharia de Nanotecnologia. Av. Horácio Macedo, 2030, Bl. G, Ilha do Fundão, Rio de Janeiro, Brazil, 21941-598.

*laisdequeiroz@yahoo.com.br

(C) Gomes L., Alves B., de Cassia Nunes R., Michel R., Ribeiro Y., da Silva F., Spinelli L., 2017
}

structure isolated from the aqueous bulk [3-5]. Physicochemical properties of both surfactant (ionic or nonionic) and viscosifier (usually a polymer) control thickness and viscosity of the viscous phase. The balance between the concentrations of these agents is crucial to supporting the structure and activity of aphrons [6].

Mainly due to the good viscosity properties, aphrons can be used for drilling directional wells constructions removing cuttings produced in downhole. CGA also has the ability of surviving during compression and recovering during decompression, so it can be also used to drill through depleted or low pressures zones [58]. As downhole pressure increases during well drilling, the aphrons are compressed and store energy without collapsing. When aphrons reach a low-pressure zone or depleted formations, they penetrate into the porous formation or into fractures, release energy and expand. Consequently, formation porous or fractures media are blocked reducing filtrate losses without damaging the formations [9]. It is possible because slow pressure changes would permit the surfactants and polymers in the aphron shell to rearrange maintaining its structure [6].

Surfactants are amphiphilic compounds that consist of both polar hydrophilic groups and hydrophobic hydrocarbon chains. Due to the thermodynamic incompatibility between different blocks in the structure, surfactants are able to reduce a system surface tension and avoid unfavorable intermolecular interactions, by self-assembling into micelles-like aggregates. This process occurs above the critical micelle concentration (CMC) in the bulk phase, and surfactants may orderly entrap other molecules within the forming structures [10-11]. Variations in the hydrophilic and hydrophobic groups generate surfactants with different physicochemical properties.

Aphrons can be formed by both ionic surfactants (that present charges in the hydrophilic groups) and nonionic surfactants (that do not have charges) depending on the application [5]. The ionic surfactants contribute to stability due to electrostatic interactions and surface forces, once charge repulsion between the ionic groups retards bubbles coalescence. Nonionic surfactants stabilize aphrons by a steric effect [12-13]. 
Sodium dodecylsulfate (SDS) [14-18], sodium dodecylbenzenesulfonate (DDBS) [19-20], cetyltrimethylammonium bromide (CTAB) [14] and hexadecyltrimethylammonium bromide (HTAB) [19-20] are examples of ionic surfactants commonly used in the formulation of aphrons based drilling fluids.

Aphrons retain the same charge as the surfactant solution from which they are generated [5, 21]. When used in drilling, ionic surfactants may interact with other components of the drilling fluid or with the formation, causing additional difficulties and affecting bubbles stability [22-23]. The use of nonionic surfactants may be favorable once they do not contribute with charges to the drilling fluid.

Poly(ethylene oxide)/poly(propylene oxide) block copolymers (nonionic surfactants) have not been as much studied for aphron production comparing with ionics ones. They have the hydrophilic part composed of a poly (ethylene oxide) (EO) block and the hydrophobic part formed by a poly (propylene oxide) (PO) block. The ratio between the blocks and structural conformation confer distinct and variable characteristics, mainly due to molecular arrangement in solutions and aggregation behavior during bubbles formation [24-25].

Viscosifiers are added to the formulation in order to enhance the stability of the CGA. Viscosity increment reduces the rate of mass transfer from the viscous water shell to the bulk phase, stabilizing the structure of the aphron $[12,16,26]$. This mass transfer induced by a surface tension gradient is known as Marangoni effect [2]. The viscous water phase also entraps gas molecules in the core [13]. Different types of viscosifier have been used, such as the partially hydrolyzed polyacrylamide (PHPA) [14], bentonite [27], styrene-ethylene copolymers [28], some polysaccharides like starch and potassium alginate, but guar gum and xanthan gum are the mostly used ones $[15,17]$.

Thus, the study of the correlation of different structures of poly(ethylene oxide)/poly(propylene oxide) block copolymers used as surfactants in CGA formulations is not found in the literature. The ratio between the blocks and structural conformation confers distinct and variable characteristics. Then, using these surfactants, the bubble formation and their characteristics (amount and size distribution) can affect the filtration loss performance.

The main objective of this work is to evaluate aphrons properties (density and viscosity) and API fluid loss, comparing a viscosifier concentration, nonionic surfactant structure and concentration with bubbles characteristics (amount and size distribution).

\section{Experimental}

\subsection{M aterials}

This study used four nonionic surfactants, supplied by Oxiteno (São Paulo, Brazil). These surfactants were used in concentrations above the CMC. Table 1 exhibits surfactants characteristics informed by a supplier. Halliburton (Rio de Janeiro, Brazil) supplied the viscosifier xanthan gum.

\subsection{Aphrons Production}

Different aphron formulations were prepared using a xanthan gum and the four types of surfactants, both in three different concentrations, in a lab barrel of distilled water $(0.351)$. In order to better observe borderline behavior, three conditions were studied:

(i) condition 1 , the most diluted $\left(2.86 \mathrm{~kg} / \mathrm{m}^{3}\right.$ of xanthan gum and surfactants in initial concentration);

(ii) condition 2, the intermediate one $\left(4.29 \mathrm{~kg} / \mathrm{m}^{3}\right.$ of xanthan and surfactants by double and a half of the initial concentration), and;

(iii) condition 3, the most concentrated $\left(5.71 \mathrm{~kg} / \mathrm{m}^{3}\right.$ of xanthan gum and surfactant by four times the initial concentration).

The concentrations of xanthan gum were used based on Petrobras standard of water-based drilling fluids composition [29]. Table 2 shows the concentrations of each surfactant used, all initial concentrations (condition 1) were above the CMC. The CMC is defined as the concentration of a surfactant in the bulk at which micelles start to form and maximum microbubbles stability is achieved above this concentration $[5,31]$.

Table 1

Surfactants characteristics

\begin{tabular}{|c|c|c|c|c|}
\hline Surfactant denomination & Molecular structure & EO units & PO units & HLB \\
\hline EO7 & $\mathrm{C}_{12} \mathrm{H}_{26}-\left(\mathrm{O}-\mathrm{CH}_{2}-\mathrm{CH}_{2}-\right)_{7}-\mathrm{OH}$ & 7 & 0 & 12.1 \\
\hline EO10 & $\mathrm{C}_{12} \mathrm{H}_{26}-\left(\mathrm{O}-\mathrm{CH}_{2}-\mathrm{CH}_{2}\right)_{10}-\mathrm{OH}$ & 10 & 0 & 13.9 \\
\hline EO3PO6 & $\mathrm{C}_{12} \mathrm{H}_{26}-\left(\mathrm{O}-\mathrm{CH}_{2}-\mathrm{CH}_{2}\right)_{3}-\left(\mathrm{O}-\mathrm{C}_{3} \mathrm{H}_{6}\right)_{6}-\mathrm{OH}$ & 3 & 6 & 5.5 \\
\hline EO6PO3 & $\mathrm{C}_{12} \mathrm{H}_{26}-\left(\mathrm{O}-\mathrm{CH}_{2}-\mathrm{CH}_{2}-\right)_{6}-\left(\mathrm{O}-\mathrm{C}_{3} \mathrm{H}_{6}\right)_{3}-\mathrm{OH}$ & 6 & 3 & 9.3 \\
\hline
\end{tabular}

Notes: EO - ethylene oxide; PO - propylene oxide; HLB - hydrophilic lipophilic balance 
Table 2

Surfactants concentrations in $\mathrm{kg} / \mathrm{m}^{3}$ used in conditions 1,2 and 3

\begin{tabular}{|c|c|c|c|}
\hline & \multicolumn{3}{|c|}{ Condition } \\
\hline Surfactant & 1 & 2 & 3 \\
\hline EO7 & 2.08 & 5.20 & 8.32 \\
\hline EO10 & 1.04 & 2.60 & 4.16 \\
\hline EO3PO6 & 0.52 & 1.30 & 2.08 \\
\hline EO6PO3 & 2.7 & 6.75 & 10.8 \\
\hline
\end{tabular}

Note: condition 1 - initial concentration of each surfactant

Surfactants density were measured by an Anton Paar densimeter, model DMA 4500M to be used in calculi of the amount of surfactant in each system.

Systems used to produce aphrons were prepared by adding the xanthan gum to the distilled water and stirring at 10,000 to $17,000 \mathrm{rpm}$ for $10 \mathrm{~min}$ in a Hamilton Beach blender. Surfactants were then added to the fluid during a second 10 minutes stirring. The resulting systems were transferred to $500 \mathrm{ml}$ high-pressure high-temperature (HPHT) filter press supplied by Fann Ins. Co. (Houston, USA). Aphrons were formed under $6.89 \cdot 10^{5} \mathrm{~Pa}$ pressure applied in the upper valve of the filter press chamber, forcing the fluids through a second lower valve [32].

Blank systems were also prepared based on aqueous solutions of xanthan gum in the concentrations of conditions 1,2 and 3. These solutions were kept under mixing during $20 \mathrm{~min}$.

All solutions were prepared in duplicates.

\subsection{Aphrons Characterization}

A Fann Model 35 Viscometer was used to characterize the rheology of the produced aphrons. This equipment has six rotation speeds $(600,300,200,100,6$ and $3 \mathrm{rpm}$ ).

The methodology to obtain aphrons density consisted in weighting an empty graduated cylinder, filling this cylinder with aphrons until a specific volume where meniscus reading was possible. Then the aphronsfilled cylinder was weighted again. The mass difference between the empty and filled cylinder provided the mass of the aphrons that was divided by the aphrons volume to obtain the density. Analyses were made in duplicates and average density was used with a standard deviation.

To obtain images of each produced aphron, we observed different samples from the same fluid under an optical microscope (Carl Zeiss Microscopy, Axio Vert.A1) with 10 times magnification. Samples were limited to the same area and height in the slides so samples volume would be reproducible. We analyzed 24 images of each produced aphron. Image analysis, in many cases, was done by the $2 \mathrm{D}$ projection of two or more bubbles: they were superimposed or in close contact demanding extra steps in order to have, their dimensions automatically measured. These steps consisted in drawing disks over each bubble in the image, moving the disks apart and then creating a new image containing only the disks. The set of disks has the same size distribution as the set of bubbles projections so the new image has a content equivalent (in size distribution) to the original image. Since the disks were moved apart each other the resulting image is well resolved. The newly generated equivalent image was converted to grayscale by using GIMP 2.8 image editor and then the number of disks and their radius were measured by the "Analyzing Particles" feature of FIJIImageJ2 $1.50 \mathrm{~b}$ software. The data obtained was then processed by a Python 3.4 script in order to classify the sizes and to generate the corresponding size distribution histograms using Matplotlib library [33-37].

\subsection{Filtration Loss Evaluation}

Tests were based on standard proceedings specifications for water-based drilling fluids of Petrobras [38]. Briefly, it consists in filling a filtration cell with aphron fluid to within $0.01-0.015 \mathrm{~m}$ of the top, approximately $0.365 \mathrm{l}$, applying $3.45 \cdot 10^{5} \mathrm{~Pa}$ and forcing it through a Watmann $\mathrm{n}^{\mathrm{o}} 50$ filter paper (with $2-5 \mu \mathrm{m}$ porous) used as a filtration medium. The filtrate is then collected into a graduated cylinder. Analyses were carried out at room temperature during $30 \mathrm{~min}$.

\section{Results and Discussion}

\subsection{Configuration Proposal for Surfactants on Microbubbles}

Aphrons multi-layered surfactant structure proposed by Sebba [1, 2], responsible for aphrons stability, could not be directly verified, although some studies about this structure thickness have already been conducted [22, 23, 39]. Moreover, there are no studies correlating aphrons layers with the EO/PO surfactants used in this work. However, it is known that steric mechanism is responsible for maintaining the integrity of the micelles formed by the nonionic surfactants [5]. 
The correlation between the structure of surfactants and the characteristics of microbubbles is related to the configuration of surfactants on a microbubbles border in contact with the bulk in an aphrons fluid. Based on the EO/PO surfactant structure $[19,40]$, this work proposes possible configurations for the surfactant molecules on microbubbles border in contact with the bulk phase (Fig. 1) that supports the discussions about aphrons properties. The hydrophilic groups of the surfactants penetrate deeper into the aqueous bulk phase when the EO chains lengths enhance from 7 to 10 units. As in EO6PO3, the insertion of $3 \mathrm{PO}$ hydrophobic groups may not anchor very well into the hydrophobic part of the micelles, reducing molecules spatial conformation and the mobility of the hydrophilic groups in the bulk phase. When comparing EO6PO3 and EO3PO6, the inversion in the quantities of polar and nonpolar groups reduces micelles interactions with the bulk phase once in EO3PO6 there are shorter hydrophilic chains interacting with aqueous bulk.

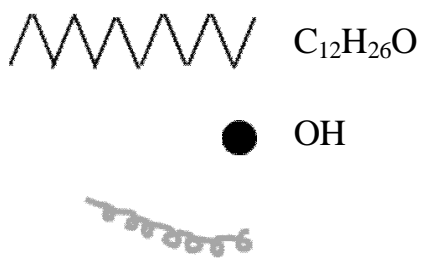

$\mathrm{EO}$

$\mathrm{PO}$

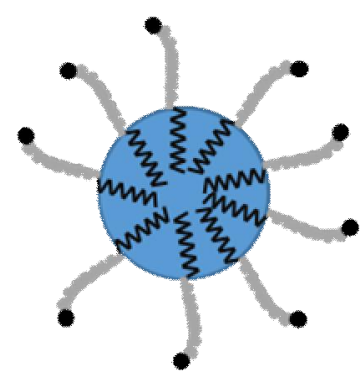

EO7

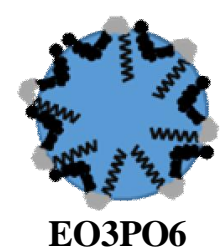

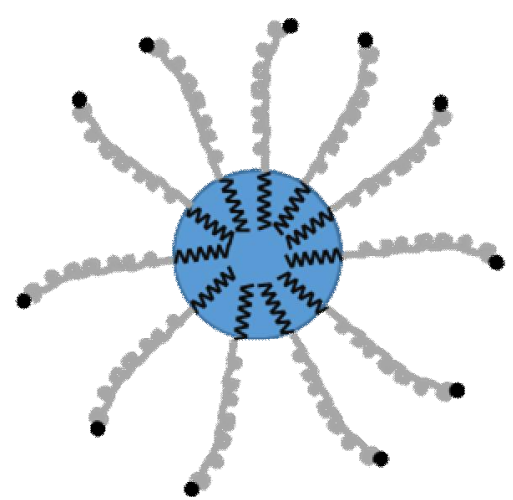

EO10

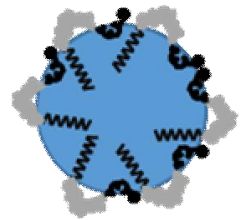

EO6PO3

Fig. 1. Configuration proposals by EO/PO nonionic surfactants on microbubbles border in contact with the bulk phase

Table 3

Aphrons analysis results

\begin{tabular}{|c|c|c|c|c|c|c|c|c|}
\hline \multirow[b]{2}{*}{ Fluids } & \multirow{2}{*}{$\begin{array}{l}\text { Density, } \\
10^{2} \mathrm{~kg} / \mathrm{m}^{3}\end{array}$} & \multicolumn{2}{|c|}{ Fann viscosity } & \multirow{2}{*}{$\begin{array}{c}\text { Size } \\
\text { distribution, } \\
\mu \mathrm{m}\end{array}$} & \multirow{2}{*}{$\begin{array}{c}\text { Average } \\
\text { diameter, } \\
\mu \mathrm{m}\end{array}$} & \multirow{2}{*}{$\begin{array}{l}\text { Number of } \\
\text { analyzed } \\
\text { bubbles }\end{array}$} & \multirow{2}{*}{$\begin{array}{l}\text { Vol. filtrate } \\
\text { reduction test, } \\
10^{-3} 1\end{array}$} & \multirow{2}{*}{$\begin{array}{c}\text { Filtrate } \\
\text { reduction } \\
\text { efficiency, } \\
\%\end{array}$} \\
\hline & & PV & YP & & & & & \\
\hline XG 1 & $9.83 \pm 0.1$ & 4 & 11 & - & - & - & $20.85 \pm 0.15$ & - \\
\hline EO7-1 & $4.19 \pm 0.0$ & 12 & 18 & $0-200$ & $73 \pm 37$ & 1850 & $14.75 \pm 0.25$ & 29 \\
\hline EO10-1 & $4.19 \pm 0.1$ & 11 & 16 & $0-240$ & $75 \pm 39$ & 1645 & $16.40 \pm 0.25$ & 21 \\
\hline EO3PO6-1 & $8.03 \pm 0.0$ & 4 & 10 & $0-140$ & $62 \pm 28$ & 156 & $36.70 \pm 0.50$ & - \\
\hline EO6PO3-1 & $4.79 \pm 0.5$ & 8 & 12 & $0-160$ & $56 \pm 27$ & 1459 & $15.75 \pm 0.15$ & 24 \\
\hline $\mathrm{XG} 2$ & $9.83 \pm 0.1$ & 7 & 16 & - & - & - & $16.1 \pm 0.10$ & - \\
\hline EO7-2 & $3.83 \pm 0.0$ & 14 & 28 & $0-240$ & $84 \pm 43$ & 1013 & $14.45 \pm 0.45$ & 10 \\
\hline EO10-2 & $4.55 \pm 0.1$ & 11 & 23 & $0-200$ & $57 \pm 26$ & 2025 & $18.50 \pm 0.10$ & - \\
\hline EO3PO6-2 & $8.39 \pm 0.0$ & 6 & 14 & $0-140$ & $60 \pm 28$ & 80 & $19.05 \pm 0.15$ & - \\
\hline EO6PO3-2 & $5.51 \pm 0.0$ & 11 & 19 & $0-220$ & $77 \pm 34$ & 853 & $13.2 \pm 0.40$ & 18 \\
\hline XG 3 & $10.2 \pm 0.1$ & 9 & 23 & - & - & - & $14.85 \pm 0.05$ & - \\
\hline EO7-3 & $4.07 \pm 0.0$ & 22 & 44 & $0-220$ & $66 \pm 33$ & 1424 & $10.20 \pm 0.20$ & 31 \\
\hline EO10-3 & $4.67 \pm 0.2$ & 19 & 29 & $0-240$ & $81 \pm 35$ & 1002 & $12.55 \pm 0.05$ & 15 \\
\hline EO3PO6-3 & $8.15 \pm 0.0$ & 7 & 20 & $0-160$ & $83 \pm 41$ & 57 & $28.85 \pm 0.35$ & - \\
\hline EO6PO3-3 & $6.11 \pm 0.0$ & 14 & 22 & $0-280$ & $70 \pm 34$ & 1088 & $10.25 \pm 0.50$ & 31 \\
\hline
\end{tabular}


The hydrophilic-lipophilic balance (HLB) is a measure of surfactants physicochemical characteristics. An arbitrary scale varies from 0 to 20 . The value of 10 is the threshold between hydrophilic and lipophilic systems [41]. Hydrophilic surfactants present high values while lipophilic surfactants present low HLB values [42, 43]. According to HLB differences (Table 1), EO10 is the most hydrophilic surfactant, followed by EO7, EO6PO3 and EO3PO6. In addition, EO10 has the lowest CMC, thus, has the structure that is most favorable to self-assemble, as shown in Fig. 1.

Each correlation between the fluid properties and API fluid loss performance was discussed based on this proposal.

\subsection{Aphrons Characterization}

Table 3 summarizes results of density, viscosity (aphrons properties), diameter, size distribution and bubbles amount (bubbles characteristics), as well as API filtrate loss for aphrons produced with EO7, EO10, EO3PO6 and EO6PO3 surfactants under the tested conditions (1, 2 and 3). The surfactants densities $(\mathrm{g} / \mathrm{ml})$ measured to determine the volume used for producing each aphrons fluid were: EO7 - 0.99; EO10 - 1.01; EO3PO6 - 0.96 and EO6PO3 - 0.98 .

Fig. 2 graphically presents the amount and the diameter of the bubbles for all systems. Fig. 3 shows micrographs of the obtained systems with 10x magnification.

\subsubsection{Density, size distribution and amount of bubbles}

The density of water-based drilling fluids are equal or superior to the density of the aqueous continuous phase $\left(10 \cdot 10^{2} \mathrm{~kg} / \mathrm{m}^{3}\right)$. Once aphrons fluids are used in drilling and depleted well interventions, it is necessary to produce aphrons that are less dense than water to maintain a well

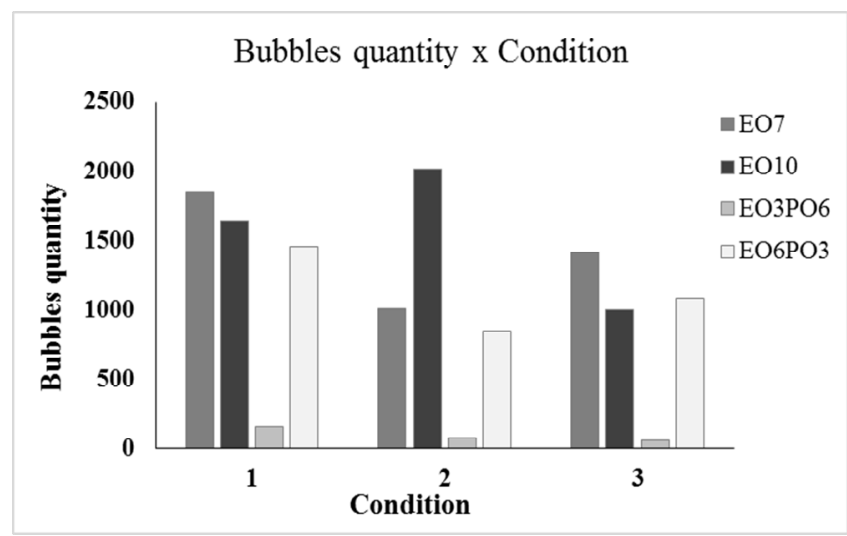

hydrostatic balance and avoid damages at the formation. Therefore, the aphrons produced in this work presented density values ranging from $3.83 \cdot 10^{2} \mathrm{~kg} / \mathrm{m}^{3}$ for the EO7 surfactant to $8.39 \cdot 10^{2} \mathrm{~kg} / \mathrm{m}^{3}$ for EO3PO6. Fig. 4 exhibits the variation in aphrons density with the tested conditions.

The increment of both gum and surfactant concentrations did not produce an uniform variation of aphrons density, with the exception of the aphron produced with EO3PO6, which density enhanced while increasing those concentrations, due to decreasing the amount of bubbles (and, consequently, the amount of air) in the system. Thus, enhancing gum and surfactant concentrations does not favor bubbles formation when using EO3PO6.

Aphrons density reduces when the amount and size of the bubbles enhance due to the higher amount of entrapped air within the bubbles instead of liquid continuous phase [26]. This kind of behavior was observed in all three conditions, with a few exceptions. For example, in aphrons formed with EO3PO6, higher density values and lower bubbles amount were observed.

EO7-2 and EO10-3 systems provided very close values of bubbles sizes and amounts; their measured densities were $3.83 \cdot 10^{2}$ and $4.67 \cdot 10^{2} \mathrm{~kg} / \mathrm{m}^{3}$, respectively. It was expected that these systems present the same density, but the difference suggests that micelles formed with EO10-3 are able to withstand higher internal pressures produced by higher gas mass in the core, what increases the density of the aphrons. Combining with the highest HLB value, the longer polar group in EO10 better stabilizes the bubbles due to stronger interactions with the aqueous bulk phase.

Comparing EO6PO3-1 and EO7-3 systems, that also present close bubbles amount and size range, the addition of 3 PO hydrophobic groups to the molecule reinforces the interaction of the molecules with the internal part of the microbubbles, withstanding higher internal pressure caused by higher incorporated gaseous mass.

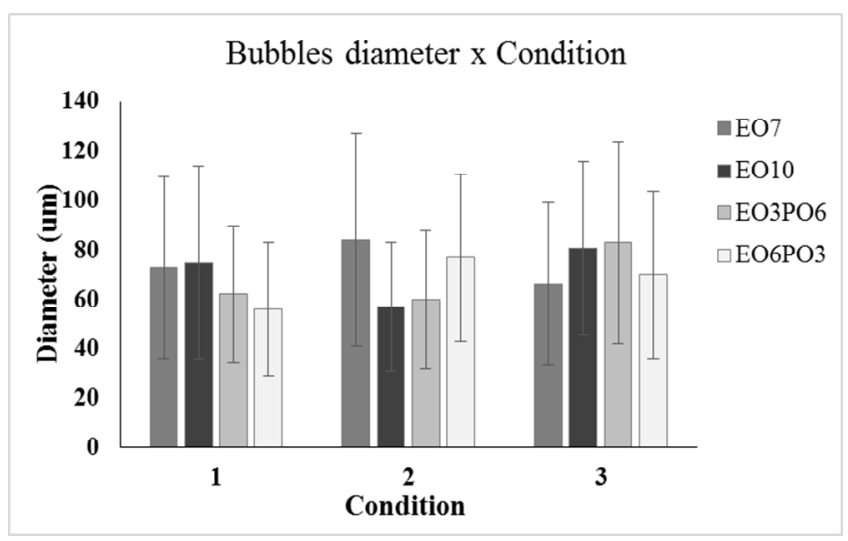

Fig. 2. Relationship between bubbles quantity, diameter and conditions 
Lais Gomes et al.

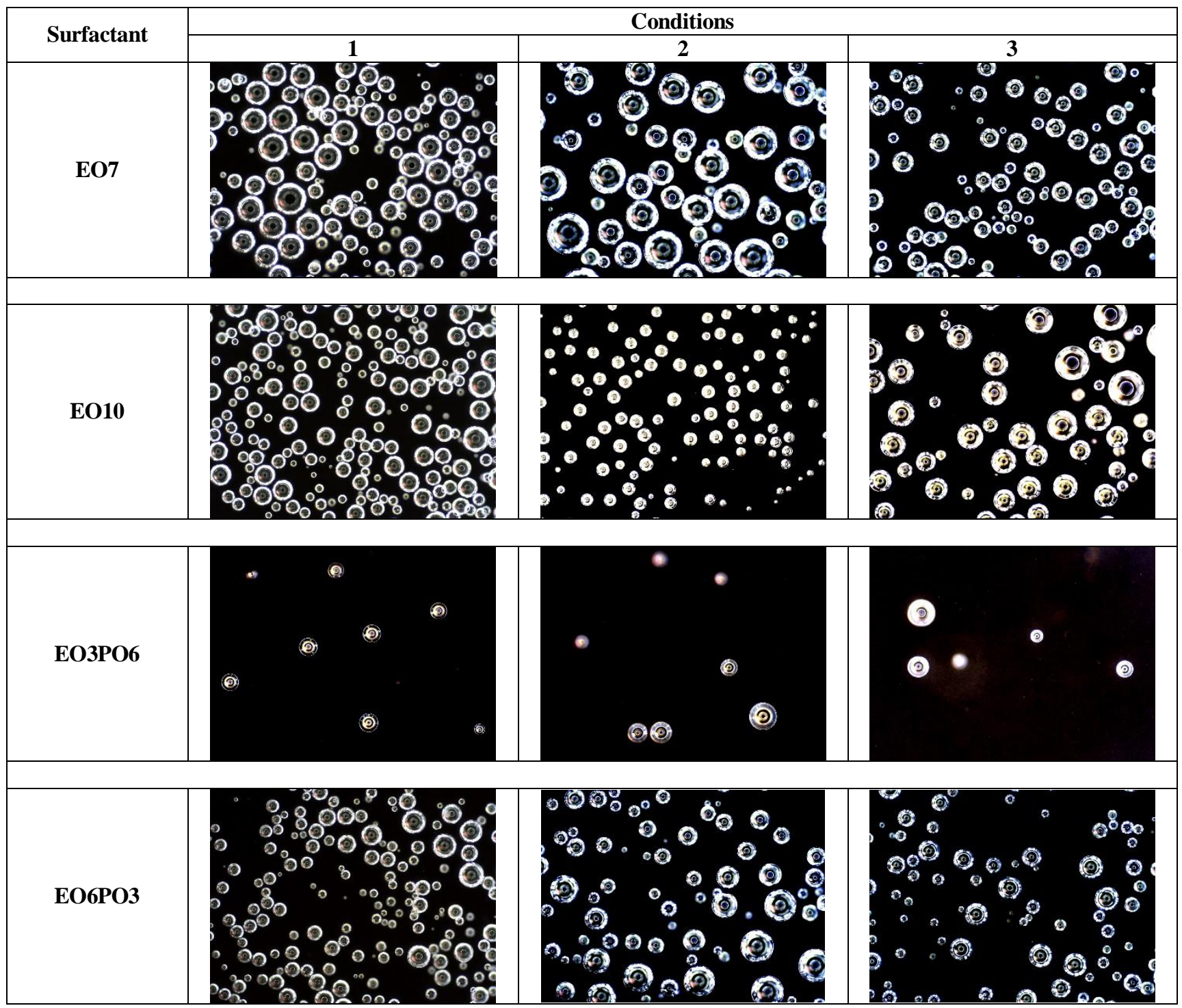

Fig. 3. Systems micrographs (10x magnification)

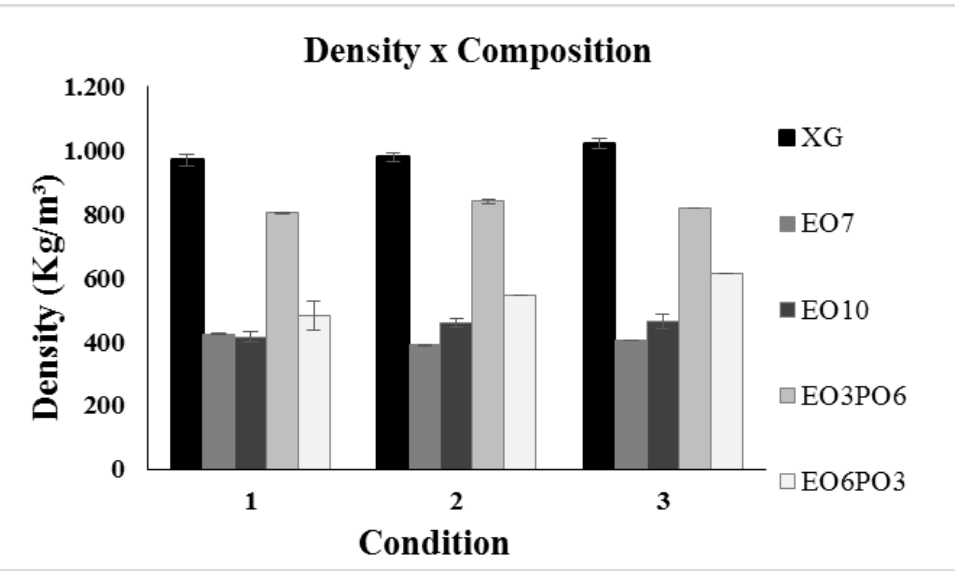

Fig. 4. Aphrons density under the tested conditions 


\subsubsection{Viscosity}

Rheological parameters of drilling fluids are very important for the well cleaning through the transportation of cutting from downhole to the surface. This field usually uses Fann rheometers because they provide fast results of reading and easy handling. Fig. 5 graphically presents the results obtained in this work with a Fann rheometer. To compare the rheology of the aphrons the parameters plastic viscosity (PV) and yield point (YP) of the Bingham plastic model were used [44].

$\mathrm{PV}$ is a rheological parameter associated with the flux caused by solid particles present within the drilling fluid [45]. In this work, PV represents the bubbles in the systems, thus, indicates bubbles amount, size and form. As all analyzed images revealed perfectly spherical bubbles, the bubbles form does not influence these work evaluations. $\mathrm{PV}$ was calculated by subtracting the $600 \mathrm{rpm}$ dial reading from the $300 \mathrm{rpm}$ dial reading on Fann viscometer [46].

YP is a measure of viscosity regarding interparticles interactions and interactions between particles and bulk phase. Here, bubbles in the systems generate the particles effects. YP describes the ability of a drilling fluid to lift cuttings out of the annulus (space between the drilling column and well walls). It was calculated by subtracting PV from the $300 \mathrm{rpm}$ dial reading on Fann viscometer [46].

As expected, viscosity increases with the increase in the concentration of viscosifier in all systems, as shown in Fig. 5. The higher the amount of polymers in the bulk, more chain entanglements occur, what enhances the resistance to flow. Regarding the surfactant type, the increasing order of viscosity was EO3PO6 < EO6PO3 < EO10 < EO7. EO10 and EO7 have stronger effect in the bulk viscosity. As diblock surfactants present hydrophobic hydrocarbon chains of the same size, their micelles self-assemble in the same manner, but EO10 micelles have longer EO hydrophilic branches towards the bulk, providing stronger interaction with the aqueous fluid, thus resisting less to the mass flow. EO3PO6 and EO6PO3 were the least effective in enhancing system viscosity. Being triblock copolymers, with the insertion of PO group, due to their molecular packing, their micelles do not have free hydrophilic groups penetrating into the bulk phase. As their HLB values are the lowest, their EO chains are, probably, not able to interact enough with the bulk phase. Thus, EO3PO6 and EO6PO3 have little effect in the system viscosity.

Usually, the system that presents higher bubbles amount, size and higher contact surface will exhibit higher PV values. The system with higher YP will be the one with higher interbubbles and bubbles-bulk phase interactions.

It was observed that $\mathrm{PV}$ increases with the amount of bubbles under condition 1 , but the same effect was not observed under conditions 2 and 3 . In condition 2 , the highest PV (14 lb/100ft ${ }^{2}$ ) was from EO7-2 sample with half of bubbles amount of the condition EO10-2 $\left(11 \mathrm{lb} / 100 \mathrm{ft}^{2}\right)$. Under condition 3, the EO10-3 sample showed higher PV than EO6PO3-3 although the lower bubbles amount. Thus, the evaluation of the systems by plastic viscosity does not characterize well the rheological behavior of aphrons.

However, YP better characterizes the systems, once the interactions interbubbles and bubbles-bulk phase are more significant than physical characteristics of aphrons.

As seen in Fig. 2, EO7 and EO10 surfactants present greater interactions with bulk phase when compared to EO3PO6 and EO6PO3 surfactants molecules, increasing the YP values. In the EO3PO6 and EO6PO3 cases, due to the deeper insertion of nonpolar group into the micelle, there are fewer interactions between the micelles and the bulk phase, enhancing the YP values.

\subsubsection{API fluid loss}

In this work, the performance of CGAs as filtrate reducers was calculated using the values for xanthan gum solution in the same concentration of the ones used under conditions 1, 2 and 3. Eq. (1) presents this relation [15].

$$
\text { Efficiency }=\frac{\text { Base fluid value }- \text { Aphronized value }}{\text { Base fluid value }} \cdot 100 \%
$$

The performance in API fluid loss depends on the average diameter and the amount of bubbles. The filtration medium used here was a Watmann $\mathrm{n}^{\circ} 50$ filter paper with porous ranging from 2 to $5 \mu \mathrm{m}$. EO7-3 and EO6PO3-3 achieved best performance by reducing filtrate loss by $31 \%$, and their average diameter of bubbles were very close to each other, 33-99 $\mu \mathrm{m}$ and 36-104 $\mu \mathrm{m}$, respectively. This indicates that bubbles, which diameter range is $33-104 \mu \mathrm{m}$, effectively block this porous range after compression by the applied pressure without destabilizing. The bubbles size range in all other systems extrapolates this optimum diameter interval $(33-104 \mu \mathrm{m})$ and does not reduce filtrate loss as well as EO7-3 and EO6PO3-3. Their sizes might reduce enough to pass through the filtrating medium under pressure, or their structure does not resist to compression.

The amount of bubbles in the system works synergistically with the diameter range in reducing filtrate loss. Two possibilities may exist:

(i) When there is an elevated amount of bubbles in a medium, the aphrons have more chance of shocking with each other and coalescing or disrupting. As steric mechanisms stabilize microbubbles formed by nonionic surfactants, an applied pressure forces bubbles against each other. The external molecules of one micelle are closer to the molecules of other micelle. Due to repulsion against the chains of the same physicochemical properties, those micelles destabilize. This behavior could be observed for EO10-2, that presented 2025 bubbles in the analyzed volume and did not reduce filtrate loss. 

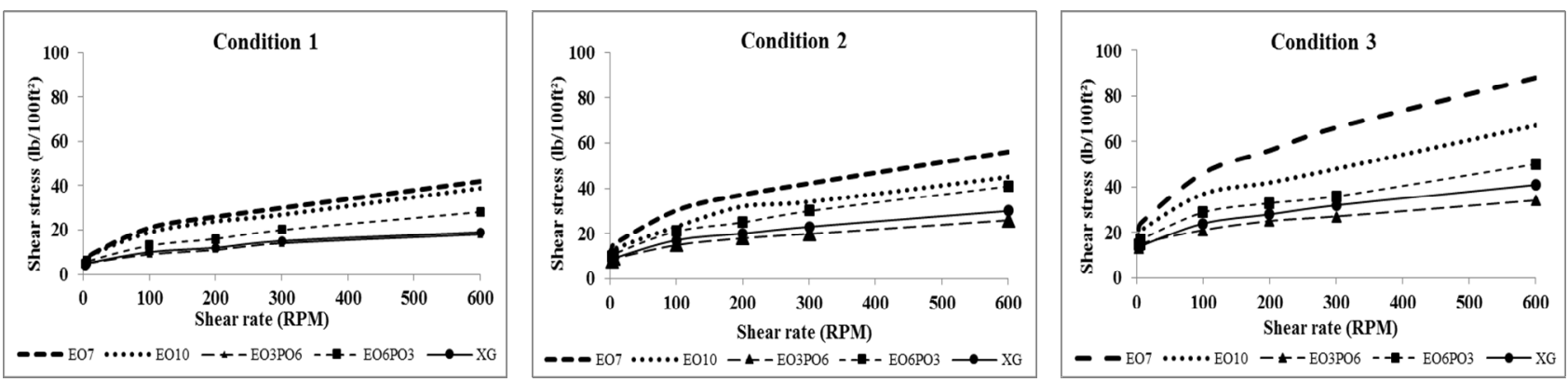

Fig. 5. Aphrons and xanthan gum rheology

(ii) Aphrons may not be enough to block porous of filtrating medium when they exist in a very low amount of bubbles. This system could be explained in EO3PO6 in all three conditions, with 50 to 150 bubbles per analyzed volume, being unable to reduce filtrate loss.

The most efficient systems in reducing API fluid loss were EO7-3, with 1424 bubbles analyzed by optical micrographs, and EO6PO3-3, with 1088 bubbles. So, for our tests, formulations that produce between 1000 and 1500 bubbles seem to be the best filtrate loss reducers. Values outside this range have lower efficiency. EO10-3 and EO6PO3-1 (with 1002 and 1459 bubbles, respectively), they reduced filtrate by only 15 and $24 \%$, probably because their bubbles were either too small to block the pore or their structure does not resist to compression.

\section{Conclusions}

Nonionic surfactants based on EO/PO block copolymers would be an alternative to produce aphrons, once they do not contribute to charging the bulk medium, and keep rheology, density and filtrate reduction characteristics that allow them to be used as drilling fluid.

Considering the definitions proposed by Sebba [1, 2], this work prepared aphrons formed by closely packed spherical bubbles, with predominant diameter size range between 10 and 100 micrometers for all conditions tested using these nonionic surfactants.

The density of aphrons is a function of the mass of air entrapped within aphrons structure formed by the hydrophilic and hydrophobic interactions of the nonionic surfactants. All systems achieved density ranging from 390 and $840 \mathrm{Kg} / \mathrm{m}^{3}$, all above the density of water $(1000$ $\mathrm{Kg} / \mathrm{m}^{3}$ ). YP parameter better describes rheological behavior of aphrons than PV. YP reflects interbubbles interactions and interactions between bubbles and bulk phase. These interactions influence more the system movement than its physical characteristics (amount, size and form of bubbles).
In the API fluid loss tests, it was observed a synergism between average size range and amount of produced bubbles. Reducing efficiency achieved 31\% with systems produced between 1088 and 1850 bubbles with diameters ranging from 33 to $104 \mu \mathrm{m}$.

The surfactants that produce aphrons with better properties and performance results were EO7 and EO6PO3. These results are related to an optimum number of EO units and an insertion of a few amount of PO units, which generate structures more resistant to compression in API tests.

\section{Acknowledgements}

We thank CNPq, CAPES and FAPERJ financial support and Oxiteno and Halliburton for donated materials.

\section{References}

[1] Sebba F.: Preparation of Biliquid Foam Compositions [in:] USP (Ed.), 1984, vol. 4486333.

[2] Sebba F.: Foams and Biliquid Foams - Aphrons. Wiley, New York 1987.

[3] Sadeghialiabadi H., Amiri M.: Coll. Surf., 2015, 471, 170. https://doi.org/10.1016/j.colsurfa.2015.01.058

[4] Tabzar A., Arabloo M., Ghazanfari M.: RJ. Nat. Gas Sci. Eng., 2015, 26, 895. https://doi.org/10.1016/j.jngse.2015.07.014

[5] Molaei A., Waters K.: Ad. Coll. Interf. Sci., 2015, 216, 36. https://doi.org/10.1016/j.cis.2014.12.001

[6] Growcock F., Belkin A., Fosdick M., Irving M. et al.: SPE Drill. Comp., 2007, 22, 74. https://doi.org/10.2118/97982-PA

[7] Catalin D., Quintana J., Blake L.: Society of Petroleum Engineering (SPE) Annual Technical Conference, USA, New Orleans, 2001, SPE 71377.

[8] Gaurina-Medimurec N., Pasic B.: Rudarsko-Geolosko-Naftni Zbornik, 2009, 21, 65.

[9] Ahmadi M., Galedarzadeh M., Shadizadeh S.: J. Nat. Gas Sci. Eng., 2015, 27, 1109. https://doi.org/10.1016/j.jngse.2015.09.056

[10] Corin K., O'Connor C.: Min. Eng., 2014, 58, 17. https://doi.org/10.1016/j.mineng.2014.01.001

[11] Lombardo D., Kiselev M., Magazu S., Calandra P.: Adv. Cond. Matt. Phys., 2015, 22, 151683.

[12] Growcock F., Simon G, Rea A., Leonard R. et al.: IADC/SPE Drilling Conference, USA, Dallas, 2004, 4. 
[13] González-Pérez A., Varela L., García M., Rodríguez J.: J. Coll. Interf. Sci., 2006, 293, 213. https://doi.org/10.1016/j.jcis.2005.06.026 [14] Cardoso J., Spinelli L., Monteiro V., et al.: Exp. Polym. Let., 2010, 4, 474. https://doi.org/10.3144/expresspolymlett.2010.60

[15] Nareh`ei M., Shahri M., Zamami M.: Saudi Arabia section Technical Symposium, Saudi Arabia, Al-Khobar, 2012, SPE 160888 .

[16] Arabloo M., Shahri M.: J. Petro. Sci. Eng., 2014, 113, 8. https://doi.org/10.1016/j.petrol.2013.12.002

[17] Zozulyaa O., Pletneva V.: Coll. Surf., 2015, 483, 232. https://doi.org/10.1016/j.colsurfa.2015.05.039

[18] Arabloo M., Shahri M.: Can. J. Chem. Eng., 2016, 94, 1197. https://doi.org/10.1002/cjce.22474

[19] Bjorndalen N., Jossy W., Alvarez J.: Int. Symposium and Exhibition on Formation Damage Control, USA, Lafayette, 2010, SPE127750.

[20] Bjorndalen N., Alvarez J., Jossy E., Kuru E.: SPE Drill. Compl., 2011, 26, 139.

[21] Hashim M.: Mukhopadhyay S., Gupta B., Sahu J.: J. Chem. Tech. Biotech., 2012, 87, 305. https://doi.org/10.1002/jctb.3691

[22] Amiri M., Woodburn E.: Chem. Eng. Res., 1990, 68, 154.

[23] Bredwell M., Worden R.: Biotech. Progr., 1998, 14, 31. https://doi.org/10.1021/bp970133x

[24] Nagarajan R.: Adv. Coll. Int. Sci., 2016, in press. https://doi.org/10.1016/j.cis.2016.12.001

[25] Riachy P., Lopez G., Emo M., Stébé M. et al.: J. Coll. Int. Sci., 2017, 487, 310. https://doi.org/10.1016/j.jcis.2016.10.053

[26] Bjorndalen N., Kuru E.: J. Can. Petrol. Technol., 2008, 47, 15. https://doi.org/10.2118/08-11-15-CS.

[27] Geng X., Hu X., Jia X.: J. Petrol. Explor. Prod. Technol., 2014, 4, 337. https://doi.org/10.1007/s13202-013-0094-6

[28] Shivharea S., Kuru E.: J. Petrol. Sci. Eng., 2014, 122, 257. https://doi.org/10.1016/j.petrol.2014.07.018

[29] Petrobras Proceeding Identification PE-5EM-00554-T, Fluido de perfuração Scol para perfurar reservatórios. Approved date: August 11, 2016.

[30] Spinelli L., Neto G., Freire L., et al.: Coll. Surf., 2010, 353, 57. https://doi.org/10.1016/j.colsurfa.2009.10.017

[31] Fu J., Cai Z., Gong Y. et al.: Coll. Surf., 2015, 484, 1. https://doi.org/10.1016/j.colsurfa.2015.07.039

[32] Spinelli L., Bezerra A., Aquino A. et al:: Macromol. Symp., 2006, 245-246, 243. https://doi.org/10.1002/masy.200651334

[33] Hunter J.: Comp. Sci. Eng., 2007, 9, 90. https://doi.org/10.1109/MCSE.2007.55

[34] Schneider C., Rasband W., Eliceiri K.: Nat. Meth., 2012, 9, 671. https://doi.org/10.1038/nmeth.2089

[35] Schindelin J., Arganda-Carreras I., Frise E.: Nat. Meth., 2012, 9, 676. https://doi.org/10.1038/nmeth.2019
[36] Python Software Foundation. Python Language Reference, version 3.4. Python 3.4 (www.python.org).

[37] GIMP team, GIMP - GNU Image Manipulation Program 20012016, GIMP 2.8 (http://www.gimp.org/).

[38] Petrobras Proceeding identification EP-1E1-00066-B - Redutor de filtrado para poços de petróleo, Aproved date: May 14, 2014.

[39] Jauregi P., Mitchell G, Varley J.: AIChE Journal, 2000, 46, 24. https://doi.org/10.1002/aic.690460105

[40] Mansur C., Spinelli L., Oliveira C. et al.: J. App. Polym. Sci. 1998, 69, 2459. https://doi.org/10.1002/(SICI)10974628(19980919)69:12<2459::AID-APP17>3.0.CO;2-S

[41] Manaargadoo-Catin M., Ali-Cherif A., Pougnas J., Perrin C.: Adv. Coll. Int. Sci., 2016, 228, 1. https://doi.org/10.1016/j.cis.2015.10.011

[42] Hassas B., Karakaş F., Çelik M.: Int. J. Min. Proc., 2014, 133, 97. https://doi.org/10.1016/j.minpro.2014.10.010

[43] Mercado R., Fuentes P.: Const. Buil. Mat., 2016, 123, 162. https://doi.org/10.1016/j.conbuildmat.2016.06.129

[44] http://www.glossary.oilfield.slb.com

[45] Machado J.: Reologia e escoamento de fluidos. Editora Interciência, Rio de Janeiro 2002.

[46] Philips A.: So you decided to be a mud engineer - An Introduction to Drilling Fluids Technology, Bakersfield, California 2011 .

Received: December 23, 2016 / Revised: M arch 23, 2017 /

Accepted: M ay 02, 2017

\section{ОДЕРЖАННЯ АФРОНІВ 3 НЕЙОННИХ ПОВЕРХНЕВО-АКТИВНИХ РЕЧОВИН: ОЦІНЮВАННЯ ВЛАСТИВОСТЕЙ І ФІЛЬТРАЦІЙНИХ ВТРАТ}

Анотація. 3 використанням нейонних ПАР при різному диференціальному тиску одержано афрони. Розподіл бульбашок за розміром проведено за допомогою оптичної мікроскопії з використанням програми FIJI-IтаgеJ2. Показано, щзо структура поверхнево-активних речовин впливають на властивості акронів (густину і в 'язкість), розподіл за розміром i кількість бульбашок. Визначення фільтрачійних втрат проведено на основі стандартних специфікачій для бурових розчинів Petrobras/Бразилія. Показано, щзо структура нейоногенних ПАР має значний вплив на властивості рідин. Для приготування систем застосовано полі(етиленоксид) з 7 частинали оксиду етилену, та полі(етиленоксид)-b-полі(пропіленоксида) з 6 частинами оксиду етилену і 3 - пропіленоксіду.

Ключові слова: афрони, нейонні поверхнево-активні речовини, бульбашки, аналіз зображень. 